\title{
Greetings From the New Editor of Clinical Thyroidology
}

\section{DEAR COLLEAGUES}

I am honored to begin my term as Editor-in-Chief of Clinical Thyroidology with this current issue. This journal, as one of the four journals of the American Thyroid Association (ATA), is uniquely tasked to provide expert commentary on the most impactful and timely scientific articles related to clinical thyroid disease.

Building on the accomplishments achieved from the leadership of Dr. Jerome Hershman, the journal will feature a substantially expanded group of Associate Editors with expertise in areas which include thyroid cancer, hypothyroidism, hyperthyroidism, thyroid autoimmunity, pediatric thyroidology, thyroid surgery, thyroid and pregnancy, iodine nutrition, oncology, and thyroid nuclear medicine. Each month, our team of multidisciplinary experts will identify and provide commentary on the "top 10 " articles in the literature that are most relevant to clinical thyroid practice. These reviews will continue to be distilled for the public and our patients in the monthly ATA publication, Clinical Thyroidology for the Public, that is prepared by Editor-in-Chief Dr. Alan Farwell and his team of contributors.

In this inaugural issue (for me), Drs. Valeria Ramundo, David Cooper, and Daniel Toft discuss articles relevant to the management of thyroid hormone replacement therapy among hypothyroid patients, while Drs. Tim Korevaar and Elizabeth Pearce review papers that assess the impact of thyroid dysfunction in pregnant women and neonates. Drs. Trevor Angell, Catherine Zhu, Masha Livhits, Michael Yeh, and Stephanie Fish provide commentaries on articles assessing the use of molecular markers in thyroid nodules. Dr. Maria Papaleontiou reviews a paper focused on fears of patients with thyroid cancer, and Dr. Brian Kim summarizes a systematic review and meta-analysis of secondary malignancies arising after radioactive iodine therapy in patients with thyroid cancer. Finally, Dr. Douglas Van Nostrand provides insightful commentary on the impact of the recently passed U.S. federal "right to try" law on the care of patients with thyroid disease.

The goal of Clinical Thyroidology is for it to be an indispensable resource for those who care for patients with both benign and malignant thyroid diseases. We very much look forward to bringing you these expert commentaries of the most clinically significant thyroid literature each month. Your feedback, comments, and questions are most welcome-I invite you to communicate them directly to me at clinicalthyroidology@thyroid.org.

With warm regards,

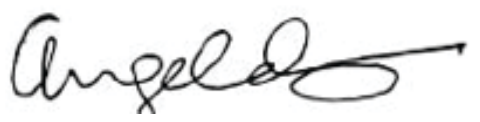

Angela M. Leung, MD, MSc

Editor-in-Chief, Clinical Thyroidology 